\title{
Kupffer Cell Stimulation of Alpha2-Macroglobulin Synthesis in Rat Hepatocytes and the Role of Glucocorticoid
}

\author{
Satoshi Kurokawa ${ }^{1}$, Hiromi Ishibashi ${ }^{1}$, Kazuhiro Hayashida ${ }^{1,2}$, \\ Yoshihiro Tsuchiya ${ }^{1,2}$, Yasuhiko Hirata ${ }^{1}$, Yoshiyuki Sakaki ${ }^{2}$, \\ Hideo Okubo ${ }^{1}$ and Yoshiyuki Niho ${ }^{1}$ \\ ${ }^{1}$ The First Department of Medicine, Faculty of Medicine and ${ }^{2}$ Research \\ Laboratory for Genetic Information, Kyushu University, Fukuoka 812, Japan
}

\begin{abstract}
When stimulated with lipopolysaccharide (LPS), primary cultures of Kupffer cells from the rat secreted a hepatocyte-stimulating factor (Kupffer factor) which induced the synthesis of $\alpha_{2}$-macroglobulin (a2M) by hepatocytes. The effect of this Kupffer factor was found only when dexamethasone was present in the hepatocyte culture medium. Dexamethasone alone stimulated the a2M synthesis, to some extent, in a dose-dependent manner. When both Dex and the Kupffer factor were added to the medium, cultured hepatocytes synthesized 100 -fold a2M, quantitative evidence that explains the in vivo phenomenon in which the serum a2M concentration increases more than 100 -fold in the acute phase. A co-culture study with hepatocytes and Kupffer cells indicated that the latter cells have a major function in the induction of a2M synthesis in vivo. A hybridization study with rat a2M cDNA showed that the concentration of mRNA increased in cultured hepatocytes in the presence of the Kupffer factor, but only when dexamethasone was present.

From these results we concluded that Kupffer cells secrete a hepatocytestimulating factor when stimulated by LPS and that glucocorticoid is essential for the induction of a2M in rat hepatocytes. The effect of the Kupffer factor and glucocorticoid appears to be regulated in the pretranslational, probably the transcriptional, phase.
\end{abstract}

Acute inflammation elicits enhanced secretion of a group of plasma proteins ("acute phase proteins") that include C-reactive protein, fibrinogen, $a_{1}$-acid glycoprotein, $\alpha_{1}$ antitrypsin, haptoglobin and serum amyloid A protein. The mechanisms for the synthesis of these proteins in liver has been investigated $(11,12,20)$, and interleukin-1 (IL-1) appears to be an inducer (23).

We made biochemical and physiological studies of $\alpha_{2}$-macroglobulin (a2M) $(5,6$, $8,9,10,14,17,18)$. This protease inhibitor is a typical acute phase protein found in rats, but not in humans. The serum concentration in rats increases from the normal value of approximately $30 \mu \mathrm{g} / \mathrm{ml}(10,17)$ to $4,000 \mu \mathrm{g} / \mathrm{ml}$ within $24 \mathrm{~h}$ of a turpentine injection. The protein increases in the blood but accumulates in inflammatory or

Abbreviations used: a2M; $a_{2}$-macroglobulin, Dex; dexamethasone, FCS; fetal calf serum, IL-1; interleukin-1, LPS; lipopolysaccharide, MEM; minimal essential medium. 
tumor tissues (18). It acts as a protease inhibitor mainly in the circulatory system rather than in the tissues (18). It also has immunomodulative activity, suppressing the lymphocyte blastogenesis induced by lectins (14).

A rapid and marked increase of a2M in serum is caused by its increased de novo synthesis in the liver $(6,19)$ and by hepatocytes $(8,9)$. The synthesis of a2M is modulated by various components, including hormones and cellular factors $(1,4,7,8,9)$. Murine IL-1 stimulates the synthesis of a2M in rat hepatocytes (2). Recently, Bauer et al. (1) and our group (8) have demonstrated that a culture supernatant of Kupffer cells has hepatocyte-stimulating activity that enhances the synthesis of a $2 \mathrm{M}$ by rat hepatocytes. The role of glucocorticoid in the induction of a2M also has been investigated in vivo $(1,4,7)$ and in vitro $(1,8)$. Little, however, is known about the regulating step of the glucocorticoid at the gene level during the induction of a2M.

A2M cDNA has been cloned by Northemann et al. (16) and in our laboratory (5). Using our cDNA as a probe, we demonstrated that the induction of a2M synthesis is regulated in the pretranslational stage (5). Factors such as hormones and chemical mediators would affect any experimental results gained from an in vivo system; therefore, the study of a2M expression with a2M cDNA in an in vitro system that uses a hepatocyte culture should provide an appropriate technique with which to determine the molecular mechanisms that function in the synthesis of acute phase proteins in hepatocytes.

We now have confirmed previous reports by Bauer et al. (1) and ourselves (8) that both glucocorticoid and a cellular factor (the Kupffer factor) are necessary for the induction of a2M. We also have shown a2M synthesis quantitatively through a radioimmunoassay that demonstrates the 100 -fold induction of a $2 \mathrm{M}$ in vitro. Such marked enhancement has not been reported previously $(1,8)$ in studies in which the immunoprecipitation of radiolabeled $\mathrm{a} 2 \mathrm{M}$ was used to measure a2M. It provides quantitative evidence with which to explain the in vivo phenomenon of the increase in serum a2M. Moreover, we have demonstrated that glucocorticoid is essential for the induction of a2M synthesis by the Kupffer cell-derived factor at both the protein and mRNA levels. Glucocorticoid and the Kupffer factor affect the induction of a $2 \mathrm{M}$ is in the pretranslational, probably the transcriptional, stage.

\section{MATERIALS AND METHODS}

Animals. Pathogen-free, male Wistar King A rats (200-300 g) housed in the Animal Center of Kyushu University were used in all our experiments.

Primary culture of hepatocytes. Hepatocytes were isolated from rat liver, according to Seglen (21) with minor modifications (8). These hepatocytes were suspended at a concentration of $8 \times 10^{5}$ cells $/ \mathrm{ml}(1 \mathrm{ml}$ per $35-\mathrm{mm}$ Falcon dish) in Eagle's modified essential medium (MEM) containing $10 \%$ fetal calf serum (FCS), $1 \mu \mathrm{M}$ insulin and $1 \mu \mathrm{M}$ dexamethasone (Dex). The medium was changed $4 \mathrm{~h}$ after plating and every $24 \mathrm{~h}$ thereafter with the fresh medium containing $1 \mu \mathrm{M}$ of Dex. When studying the effect of Dex on a2M synthesis, that compound was omitted from the medium for $24 \mathrm{~h}$ before the experiment.

To obtain a pure hepatocyte preparation, the cell suspension was layered on $50 \%$ isotonic Percoll solution then centrifuged at $2,000 \times \mathrm{g}$ for $30 \mathrm{~min}$ at $4^{\circ} \mathrm{C}$. Hepatocytes were collected from the fraction with a specific gravity between 1,080 to 1,090, just above the lowest layer formed by the red blood cells.

Primary culture of Kupffer cells. Non-parenchymal cells were isolated from rat liver 
by perfusion of $0.2 \%$ pronase in situ (8) then fractionated on a Percoll self-generated gradient. The liver cell suspension was mixed with $35 \mathrm{ml}$ of $50 \%$ isotonic Percoll solution diluted with phosphate-buffered saline and the culture medium. The centrifuge tube containing this suspension was then spun at $20,000 \times \mathrm{g}$ for $30 \mathrm{~min}$ at $4{ }^{\circ} \mathrm{C}$. The fraction containing nonparenchymal cells was collected and washed twice with Hanks' solution, after which the concentration was adjusted to $5 \times 10^{5}$ cells $/ \mathrm{ml}$ in RPMI 1640 containing $10 \%$ heat-inactivated FCS. Samples of $1 \mathrm{ml}$ were placed in a $35-\mathrm{mm}$ plastic dish and, after $24 \mathrm{~h}$ of incubation, the dish was rinsed with $\mathrm{Ca}^{2+}, \mathrm{Mg}^{2+}$-free phosphate-buffered saline, which removed all nonadhering cells. Fresh medium was then added, and incubation continued in $5 \% \mathrm{CO}_{2} /$ air at $37^{\circ} \mathrm{C}$. The adhering cells had $\mathrm{Fc}$ and $\mathrm{C}_{3}$ receptors, and therefore were considered Kupffer cells (15).

Co-culture of hepatocytes and Kupffer cells. Parenchymal cells were seeded at a concentration of $5.0 \times 10^{5}$ cells per ml in MEM containing $10 \%$ FCS, $1 \mu \mathrm{M}$ Dex and $1 \mu \mathrm{M}$ insulin. After incubation for $48 \mathrm{~h}$, the culture medium was removed and freshly isolated Kupffer cells were added at a concentration of $5 \times 10^{5}$ per $\mathrm{ml}$ in RPMI 1640 containing $10 \%$ FCS, after which incubation was continued for $24 \mathrm{~h}$. The following experiments were performed thereafter:

Preparation of the Kupffer cell-derived hepatocyte-stimulating factor (Kupffer factor). Kupffer cells obtained as described above were cultured for $24 \mathrm{~h}$ with $50 \mu \mathrm{g}$ of lipopolysaccharide (LPS). Supernatants were collected and pooled for use as the Kupffer factor.

Radioimmunoassay of a2M. The concentration of a2M in the culture medium was measured by a radioimmunoassay as described elsewhere (10).

Isolation of RNA. The total cellular RNA in the cultured hepatocytes was extracted by the guanidium thiocyanate/cesium chloride procedure of Chirgwin et al. (3).

Dot blot hybridization. The total RNA was denatured with glyoxal (13) then applied to a nylon membrane as described elsewhere (5). These membranes were baked at $80^{\circ} \mathrm{C}$ for $2 \mathrm{~h}$ then hybridized with nick-translated DNA at $42^{\circ} \mathrm{C}$ in $5 \times \mathrm{SSC}, 50 \mathrm{mM}$ sodium phosphate (pH 6.5 ), $0.02 \%$ bovine serum albumin, $0.02 \%$ Ficoll, $0.02 \%$ polyvinylpyrrolidone and $250 \mu \mathrm{g} / \mathrm{ml}$ of sonicated salmon sperm DNA (24). After hybridization, the nylon membranes were washed 4 times with $2 \times \mathrm{SSC}$ and $0.1 \%$ SDS for $5 \mathrm{~min}$ at room temperature then twice with $0.1 \times \mathrm{SSC}$ and $0.1 \% \mathrm{SDS}$ at $50^{\circ} \mathrm{C}$ for $15 \mathrm{~min}$, after which they were exposed to $\mathrm{X}$-ray film at $-70^{\circ} \mathrm{C}$.

\section{RESULTS}

Because the a2M secreted in the culture medium represents the a2M synthesized de novo in cultured hepatocytes (8) and because the fresh culture medium contained no a2M (as determined by the radioimmunoassay), the a $2 \mathrm{M}$ in the medium was considered to be a2M synthesized by the hepatocytes.

We first studied the daily changes in the amount of a2M synthesized by primary cultures of rat hepatocytes. With $1 \mu \mathrm{M}$ Dex in the culture medium, the synthesis of a2M was $127.0 \pm 8.0 \mu \mathrm{g} / 10^{6}$ hepatocytes $/ 24 \mathrm{~h}$ on the first day, but this value decreased rapidly (Table 1 ); on the 5 th day a2M synthesis was only $0.5 \mu \mathrm{g} / 10^{6}$ hepatocytes $/ 24 \mathrm{~h}$.

To examine the effect of Kupffer cells on hepatocytes in vivo, we co-cultured pure hepatocyte preparations with Kupffer cells, then examined the effect of LPS on the synthesis of a2M. In the pure hepatocyte culture, LPS did not enhance the synthesis of a $2 \mathrm{M}$, in the presence or absence of Dex, but Dex alone slightly enhanced this 
TABLE 1. TIME COURSE OF a2M SYNTHESIS BY PRIMARY CULTURES OF RAT HEPATOCYTES

\begin{tabular}{cc} 
Culture Day & $\begin{array}{c}\text { a2M synthesis } \\
\left(\mu \mathrm{g} / 10^{6} \text { hepatocytes } / 24 \mathrm{~h}\right)\end{array}$ \\
\hline 1 & $127.0 \pm 8.0$ \\
2 & $87.4 \pm 15.4$ \\
3 & $42.3 \pm 5.6$ \\
4 & $16.7 \pm 2.1$ \\
5 & $0.5 \pm 0.1$ \\
\hline
\end{tabular}

Following the first medium change $4 \mathrm{~h}$ after plating; the hepatocytes were incubated in MEM containing $1 \mu \mathrm{M}$ Dex. The medium was exchanged every $24 \mathrm{~h}$ thereafter with fresh medium as described in Materials AND Methods. The a2M secreted into the medium was measured by a radioimmunoassay. Each value is the mean \pm S.D. of four determinations.

synthesis. In contrast, when hepatocytes and Kupffer cells were co-cultured, $50 \mu \mathrm{g} / \mathrm{ml}$ of LPS markedly stimulated the synthesis of a2M when Dex was added to the medium (Fig. 1). When no Dex was present, there was little increase in a2M synthesis.

We next analyzed the effects of Dex and the supernatant of LPS-activated Kupffer cells (the Kupffer factor) on a2M synthesis in cultured hepatocytes. Dex alone slightly enhanced the synthesis of a2M, which effect was dose-dependent above $10^{-9} \mathrm{M}$ (Fig. 2 and 3). The Kupffer factor alone had little effect on the enhancement of the synthesis of a2M (Fig. 3), but it did have a potent stimulatory effect on a2M synthesis by hepatocytes when Dex was present. This effect appeared to depend on the concentration of the Kupffer factor present (Table 2). When cells were treated with $50 \mu \mathrm{g} / \mathrm{ml}$ of LPS, a2M was synthesized at $117.8 \mu \mathrm{g} / 10^{6}$ hepatocytes $/ 24 \mathrm{~h}$, almost 100 -fold the amount synthesized in the absence of both the Kupffer factor and Dex.

We then determined whether these factors act in the pretranslational stage. We

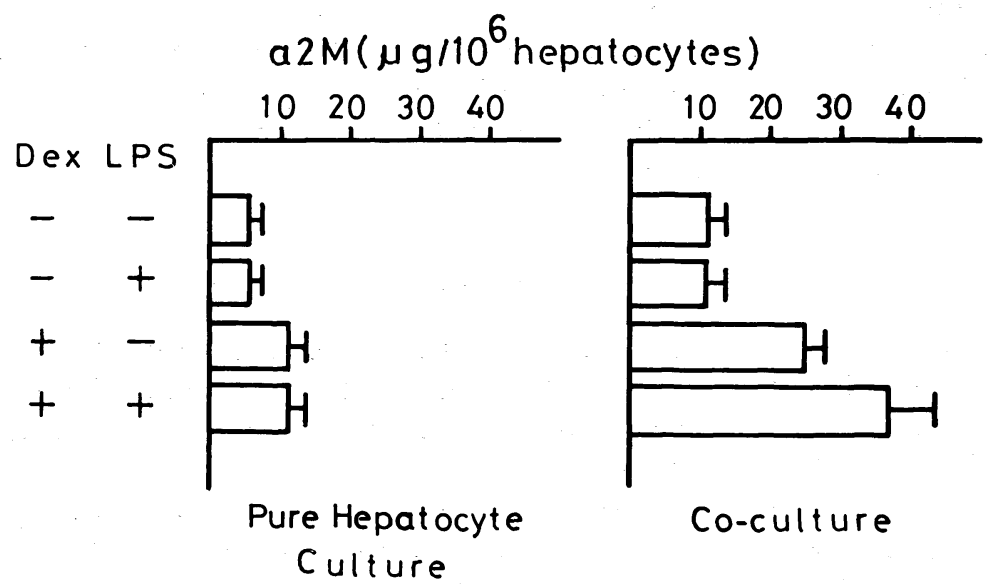

Fig. 1. Effects of LPS on the synthesis of a2M in a pure hepatocyte culture (left) and in a coculture of hepatocytes with Kupffer cells (right). In the pure hepatocyte culture, 4-day-old cultures of hepatocytes were incubated with, or without, $1 \mu \mathrm{M}$ of Dex, $50 \mu \mathrm{g}$ of LPS or both. In the coculture system, 4-day-old cultures of hepatocytes were incubated with Kupffer cells, in the presence of $50 \mu \mathrm{g}$ LPS. Dex was left out of the medium in both culture systems $24 \mathrm{~h}$ before the experiments were done. The a2M secreted in the medium was measured by a radioimmunoassay. Each column represents the mean \pm S.D. of 4 determinations. 


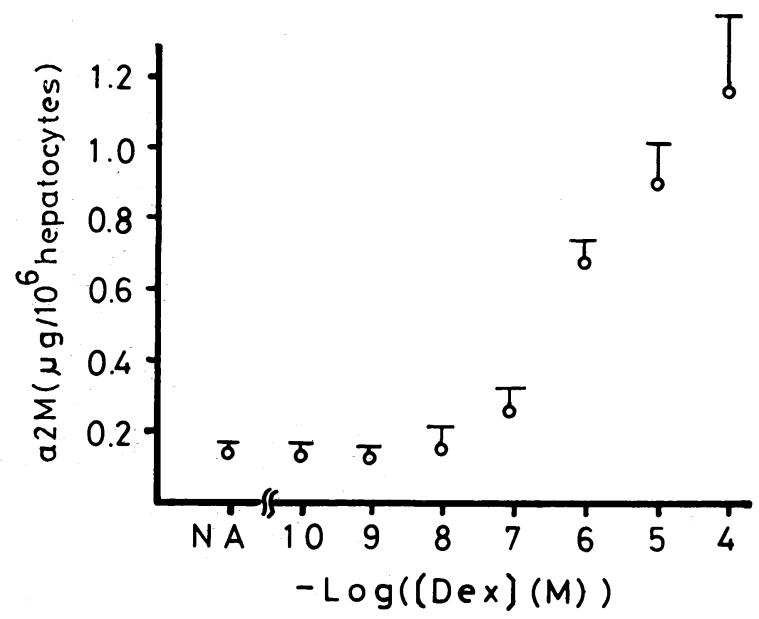

Fig. 2. Dose-response curve showing the effect of Dex on a2M synthesis. Hepatocytes from 5-day-old cultures were used. Dex was omitted from the medium $24 \mathrm{~h}$ before the experiments were done. Each point and bar represents the mean \pm S.D. of 4 determinations.

isolated the total RNA from hepatocytes (stimulated by Dex, the Kupffer factor, or both) and measured the amount of a2M mRNA present by dot blot analysis. The concentration of a2M mRNA was increased approximately 125 -fold by an addition of the Kupffer factor in the presence of Dex (Fig. 4), but an addition of the Kupffer factor alone did not increase the mRNA. An addition of $1 \mu \mathrm{M}$ of Dex alone produced 8- to 16-fold enhancement. We concluded that the Dex and the Kupffer factor affect a2M induction in the pretranslational stage, possibly in the transcriptional phase.

\section{DISCUSSION}

Recent investigations have shown that the synthesis of acute phase proteins is elicited in liver by IL-1, a macrophage-derived cytokine $(22,23)$. Because Kupffer

TABLE 2. DOSE DEPENDENCE OF THE EFFECT OF THE KUPFFER FACTOR ON a2M SYNTHESIS

\begin{tabular}{ccc}
$\begin{array}{c}\text { Kupffer factor } \\
(\mu \mathrm{l} / \mathrm{ml})\end{array}$ & $\begin{array}{c}\text { Dex } \\
(\mu \mathrm{M})\end{array}$ & $\begin{array}{c}\text { a2M synthesis } \\
\left(\mu \mathrm{g} / 10^{6} \text { hepatocytes/24 h) }\right.\end{array}$ \\
0 & 0 & $1.2 \pm 0.2$ \\
50 & 0 & $1.4 \pm 0.2$ \\
0 & 1 & $18.6 \pm 5.3^{\mathrm{a}}$ \\
5 & 1 & $36.5 \pm 2.7^{\mathrm{a}}$ \\
10 & 1 & $48.0 \pm 3.0^{\mathrm{a}}$ \\
20 & 1 & $61.0 \pm 4.0^{\mathrm{a}}$ \\
30 & 1 & $99.8 \pm 24.2^{\mathrm{a}}$ \\
50 & 1 & $117.8 \pm 16.6^{\mathrm{a}}$ \\
\hline
\end{tabular}

Various concentrations of the Kupffer factor were added to 4-day-old hepatocyte cultures with, or without, $1 \mu \mathrm{M}$ of Dex. The a2M secreted in the medium was measured by a radioimmunoassay. The Kupffer factor was prepared as described in Materials and Methods. Dex was omitted from the hepatocyte culture medium for $24 \mathrm{~h}$ before each experiment. Values are the means \pm S.D. of 4 determinations. aSignificantly different $(p<0.001)$ when compared with the top row (Student's test). 


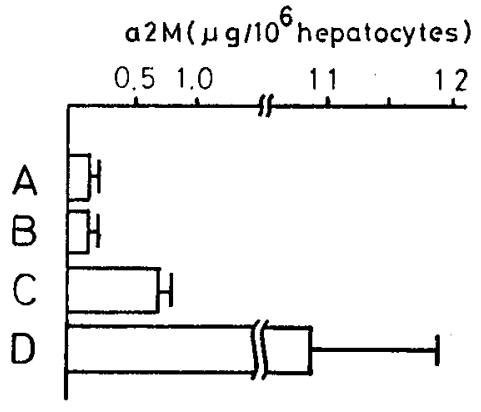

Fig. 3.
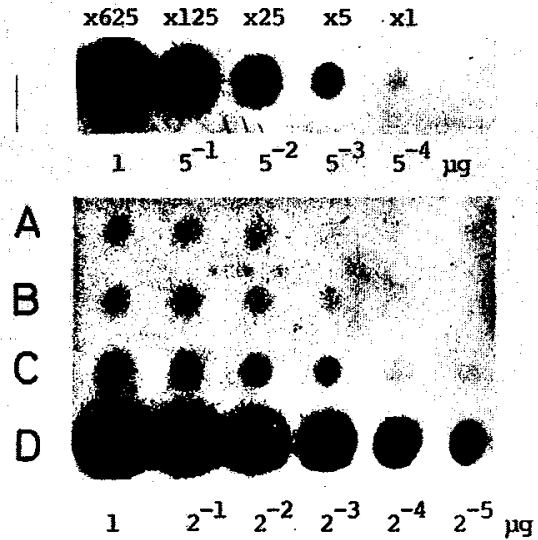

Fig. 4.

Fig. 3. Effects of Dex and the Kupffer factor on a2M synthesis. A: no additions (control), B: plus $50 \mu \mathrm{l} / \mathrm{ml}$ of the Kupffer factor, C: plus $1 \mu \mathrm{M}$ of Dex, D: plus $1 \mu \mathrm{M}$ of Dex and $50 \mu \mathrm{l} / \mathrm{ml}$ of the Kupffer factor. Hepatocytes from 5-day-old cultures were incubated with, or without, $50 \mu 1$ of the Kupffer factor, $1 \mu \mathrm{M}$ of Dex, or both. The a2M secreted in the medium was measured by a radioimmunoassay. Each column represents the mean \pm S.D. of 4 determinations.

Fig. 4. Dot blot analysis of the a2M mRNA. The total RNA isolated from primary cultures of hepatocytes was placed on a nylon membrane. The uppermost row shows the standard RNA extracted from the liver of a turpentine-injected rat in a 5-fold serial dilution (the first dot contains $1 \mu \mathrm{g}$ of total RNA). RNA preparations A to D were taken from the hepatocytes described in Fig. 3. The first dot contains $1 \mu \mathrm{g}$ of total RNA, the others sequential 2-fold serial dilutions.

cells are the major macrophage-phagocyte system in the liver and are in close proximity to hepatocytes, interest has been focused on their role in acute phase responses. Recently, Bauer et al. (1) as well as our group (8) found that supernatants from LPS-stimulated Kupffer cells from rats show hepatocyte-stimulating activity by inducing a2M synthesis. Recombinant IL-1 also has been demonstrated to stimulate a2M synthesis by directly affecting hepatocytes (2).

Co-culture experiments demonstrated that an addition of LPS to the hepatocyte culture medium stimulated the synthesis of a2M, which suggests a role for LPS. LPS, itself, did not, however, directly cause hepatocytes to begin a2M synthesis, rather it worked via the Kupffer cells by stimulating them to secrete a hepatocytestimulating factor into the culture medium.

Our study has provided quantitative evidence for a2M synthesis by hepatocytes upon stimulation with Dex, the Kupffer factor or both. When both Dex and the supernatant of Kupffer cells were added to the medium, cultured hepatocytes synthesized a2M that was 100-fold the value found for the control hepatocytes incubated without a combination of the Kupffer factor and Dex. This marked difference was not found when a2M synthesis was measured by the immunoprecipitation of radiolabeled a2M $(1,8)$. Thus, we here have shown an important function of glucocorticoid and a cellular factor (the Kupffer factor) in the induction of a $2 \mathrm{M}$ in vivo which shows that serum a $2 \mathrm{M}$ increases more than 100 -fold in the acute phase. 
The stimulatory effect of the Kupffer factor on a2M synthesis was found only when there was Dex in the culture medium. When Dex was not present, no increase in a2M synthesis took place with the Kupffer factor alone. Similar results have been reported for other assay methods $(1,8)$ and in vivo $(1,7,17)$. In adrenalectomized or hypophysectomized rats, which have few endogenous glucocorticoids, no increase in serum a2M took place after a turpentine injection, but with a supplement of Dex, the response became normal $(1,7)$.

We confirmed this by measuring the a2M mRNA present in the hepatocytes with a2M cDNA. This mRNA increased to 125 -fold the value for the control in the presence of the Kupffer factor and Dex, but there was no increase with the Kupffer factor alone. Quantitative differences in the increases in the a2M protein and the mRNA produced by this stimulation are explained by differences in the turnover rate, the rate for mRNA being higher than that for the protein.

The mechanism by which glucocorticoid induces the synthesis of acute phase proteins is postulated to be 1) production of an increase in the rate of transcription of specific genes, or 2) the stabilization of specific mRNA. Recent studies with $\alpha_{1}$ acid glycoprotein have demonstrated that this glucocorticoid stimulates the accumulation of $\alpha_{1}$-acid glycoprotein mRNA by inducing an RNA-processing factor that facilitates the production of stable transcripts (25). Our study demonstrates that the expression of the effect of Dex on a2M synthesis takes place in the pretranslational stage, possibly in the transcriptional phase. Further investigation of cloned a2M genomic DNA coupled with the in vitro system is being made.

Acknowledgments. We thank M. Ohara for her comments on the manuscript. This research work was supported in part by a Grant-in-Aid from the Ministry of Education, Culture and Science of Japan (No. 58570322).

\section{References}

1. Bauer, J., M. Birmelin, G.-H. Northoff, W. Northemann, T.-A. Tran-Thi, H. Ueberberg, K. DeCKer and P.C. HeINRICH. Induction of rat $\alpha_{2}$-macroglobulin in vivo and in hepatocyte primary cultures: synergistic action of glucocorticoids and a Kupffer cell-derived factor. FEBS Lett. 177, 89-94, 1984

2. Bauer, J., W. Weber, T.-A. Tran-Thi, G.-H. Northoff, K. Decker, W. Gerok and P.C. HeINRICH. Murine interleukin 1 stimulates $\alpha_{2}$-macroglobulin synthesis in rat hepatocyte primary cultures. FEBS Lett. 190, 271-274, 1985

3. Chirgwin, J.M., A.E. Przybyla, R.J. Macdonald and W.J. Rutter. Isolation of biologically active ribonucleic acid from sources enriched in ribonuclease. Biochemistry 18, 52945299, 1979

4. Eddington, C.L., H.F. Upchurch and R.F. KAMPSChMidt. Quantitation of plasma $\alpha_{2}$-AP globulin before and after stimulation with leukocytic extracts. Proc. Soc. Exp. Biol. Med. 139, 565-569, 1972

5. Hayashida, K., H. Okubo, M. Noguchi, H. Yoshida, K. Kangawa, H. Matsuo and Y. SAKAKI. Molecular cloning of DNA complementary to rat $a_{2}$-macroglobulin mRNA. $J$. Biol. Chem. 260, 14224-14229, 1985

6. Hayashida, K., Y. Tsuchiya, S. Kurokawa, M. Hattori, H. Ishibashi, H. Okubo and Y. SAKAKI. Expression of rat $\alpha_{z}$-macroglobulin gene during pregnancy. J. Biochem. (Tokyo) 100, 989-993, 1986

7. Heim, W.G. and S.R. Ellenson. Adrenal cortical control of the appearance of rat slow alpha 2 -globulin. Nature 1260-1261, 1967

8. Hirata, Y., H. Ishibashi, H. Kimura, K. Hayashida, M. Nagano and H. Okubo. $\alpha_{2}-$ 
macroglobulin secretion enhanced in rat hepatocytes by partially characterized factor from Kupffer cells. Inflammation 9, 201-209, 1985

9. Hirata, Y., S. Kurokawa, H. Ishibashi, K. Hayashida, H. Kimura, M. Nagano and H. Окиво. Polymorphonuclear leukocytes and the induction of $a_{2}$-macroglobulin synthesis. J. Clin. Lab. Immunol. 21, 125-130, 1986

10. IshibaShi, H., K. HaYASHIDA and H. OKUBO. Alpha 2 macroglobulin. In Methods in Enzymology; a volume of immunochemical techniques, eds. Di SABATo, G., J. J. LANGONE and H. VAN Vunakis, Academic Press, New York, in press

11. KoJ, A. Acute phase reactants. Their synthesis, turnover and biological significance. In Structure and Function of Plasma Proteins. ed. Allison, A.C., Plenum Press, London, pp. 77-131, 1974

12. Kushner, I. C-reactive protein and the plasma protein response to tissue injury. In Ann N Y Acad Sci, Vol. 389, eds. Kushner, I., J.E. Volanakis and H. Gewurz, The New York Academy of Science, New York, pp. 39-48, 1982

13. Mcmaster, G.K. and G.G. Carmichael. Analysis of single- and double-stranded nucleic acids on polyacrylamide and agarose gels by using glyoxal and acridine orange. Proc. Natl. Acad. Sci. USA 74, 4835-4838, 1977

14. Miyanaga, O., H. Okubo, J. Kudo, T. Ikuta and Y. Hirata. Effect of $\alpha_{2}$-macroglobulin on the lymphocyte response. Immunology 47, 351-356, 1982

15. Munthe-KaAs, A.C. Endocytosis studies on cultured rat Kupffer cells. In Kupffer Cells and Other Sinusoidal Cells. eds. WISSE, E. and D. L. KNooK, Elsevier Biomedical Press, Amsterdam, pp. 325-332, 1977

16. Northemann, W., M. Heisig, D. Kunz and P.C. Heinrich. Molecular cloning of cDNA sequences for rat $a_{2}$-macroglobulin and measurement of its transcription during experimental inflammation. J. Biol. Chem. 260, 6200-6205, 1985

17. Okubo, H., O. Miyanaga, M. Nagano, H. Ishibashi, J. Kudo, T. Ikuta and K. Shibata. Purification and immunological determination of $a_{2}$-macroglobulin in serum from injured rats. Biochim. Biophys. Acta 668, 257-267, 1981

18. OKubo, H., H. Ishibashi, K. Shibata, K. Tsuda-Kawamura and T. Yanase. Distribution of $a_{2}$-macroglobulin in normal, inflammatory, and tumor tissues in rats. Inflammation 8, 171-179, 1984

19. SARCione, E.J. and A.E. Bogden. Hepatic synthesis of alpha 2 (acute phase)-globulin of rat plasma. Science 153, 547-548, 1966

20. Schreiber, G. and G. Howlett. Synthesis and secretion of acute phase proteins. In Plasma Protein Secretion by the Liver. eds. Glaumann, H, T. Peters, Jr, and C. Redman, Academic Press, New York, pp. 423-449, 1983

21. Seglen, P.O. Preparation of isolated rat liver cells. In Methods in Cell Biology, Vol. 13, ed. Prescott, D.M., Academic Press, New York, pp. 29-82, 1972

22. Selinger, M.J., K.P.W.J. Mcadam, M.M. Kaplan, J.D. Sipe, S.N. Vogel and D.L. RoSENTREICH. Monokine-induced synthesis of serum amyloid A protein by hepatocytes. Nature 285, 498-500, 1980

23. Sztein, M.B., S.N. Vogel, J.D. Sipe, P.A. Murphy, S.B. Mizel, J.J. Oppenheim and D.L. Rosentreich. The role of macrophages in the acute-phase response: SAA inducer is closely related to lymphocyte activating factor and endogenous pyrogen. Cell. Immunol. 63, 164-176, 1981

24. Thомаs, P.S. Hybridization of denatured RNA and small DNA fragments transferred to nitrocelullose. Proc. Natl. Acad. Sci. USA 77, 5201-5205, 1980

25. VANNICE, J.L., J.M. TAYloR and G.M. RINGOLD. Glucocorticoid-mediated induction of $a_{1}$ acid glycoprotein: Evidence for hormone-regulated RNA processing. Proc. Natl. Acad. Sci. USA 81, 4241-4245, 1984 